\title{
The Developmental Bottleneck and Breakthrough of Government Affairs Micro-blog in Colleges and Universities
}

\author{
M. J. DUAN \& Y. B. DONG \\ Mudanjiang Normal University, Mudanjiang, Heilongjiang, China
}

\begin{abstract}
Nowadays, government affairs micro-blog is really advancing triumphantly. Government affairs micro-blog has features of a more positive information release, an increasing demand of interaction and the gradual appearance of real-name leading, etc. At the same time, there exist problems like unitary information content. To breakthrough the bottlenecks facing the development of government affairs microblog in colleges and universities, we should have it closely combined with the practical work in colleges and universities, carry out information release working mechanism, improve the enthusiasm of the participants, implement the content settling and managing mechanism of micro-blog, and actively carry out the policy of real-name micro-blog among leading cadres.
\end{abstract}

KEYWORD: Uiversities and Colleges; Gvernment affairs micro-blog

In recent years, government affairs micro-blog (also called e-government micro-blog or just weibo) has a rapid development, giving full play to its unique advantages in the social management, information disclosure, public opinion guidance, listening to the people, effective communication, etc. So is the case with the development of government affairs microblog in colleges and universities. The latter has a booming development in just a couple of years and has obtained a good effect; meanwhile, it also encounters bottleneck problems that restrain its progression.

\section{THE PRESENT SITUATION AND CHARACTERISTICS OF GOVERNMENT AFFAIRS MICRO-BLOG IN COLLEGES AND UNIVERSITIES}

Under the push of government departments, institutions of higher learning in our country have now opened e-government micro-blog because university leaders and departments also fully recognize the important role of weibo. Copared with opening, however, the actual use is not satisfactory.

\subsection{The information release is more positive}

Universities and colleges in our country have gradually realized the importance of weibo among college students and in social public communication.
Weibo can be used actively to release relevant information in a timely manner in times of hotspots, difficulties and emergencies that interest college students and the social public. In dealing with problems and answering the questions raised in weibo, colleges and universities act more positively. Generally, the issue will be solved in time or a relatively satisfactory answer will be given to the questioner.

\subsection{The demand of interaction is increasing}

Colleges and universities are the main place for college students to learn and live. College years are the key stage throughout college students' life span. Therefore, there is a large demand of weibo interaction among college students - a demand of all matters, big and small, and multifarious. The contents are often closely connected with the basic aim of teaching, which brings a huge challenge to the management and running of the government affairs micro-blog in colleges and universities.

\subsection{The information content is unitary}

Of course, we can also see that some colleges and universities are not positively involved in the use of government affairs micro-blog, for the release of information content is relatively unitary and the absolute quantity is not very large. This is reflected as follows: there are no titles for the articles in the 
blog and no specific college's own characteristics. Government affairs micro-blog is not employed as an effective instrument in the management, ideological and political education work of college students, but is merely used as a kind of emergency tool.

\subsection{Real-name leading gradually appears}

Here comes the good news: staffs at the core of leadership in many colleges and universities, especially elite schools, have gradually been aware of the positive role played by microblog in carrying forward the social positive energy, such as propaganda explanation, public opinion guidance, communication with each other and humanistic care. The phenomenon of leaders' using weibo under real name gradually arises and is flourishing; some even have driven the enthusiasm of weibo among all the teachers and students.

\section{THE DEVELOPMENTAL BOTTLENECK FACING THE UNIVERSITY} ADMINISTRATIVE MICRO-BLOGGING

In the process of progression, government affairs micro-blog in colleges and universities also faces some developmental bottleneck. Problems arose in the operation process of government affairs microblog that confuse relevant staff members in colleges and universities. These problems and the confusion they brought greatly affect the long-term healthy development of government affairs micro-blog directly or indirectly.

\subsection{The lack of effective connection with actual work}

Due to different functions, different college teaching and managing departments have different understanding and use of weibo. But the common problem is that there is no effective connection between the work of the department and the unique function of weibo, and that there hasn't formed a long-term benign interactional mechanism. Specific performance is, on the one hand, the use of weibo is often confined within the school propaganda and other related departments; the employment in other functional departments at school is not ubiquitous. The use of weibo by propaganda departments of universities and colleges, on the other hand, tends to be temporary and intermittent, and hasn't formed a long-term mechanism, thus does not have the continuity and sustainability.

\subsection{The confusion of information release and content openness}

With the application and popularization of weibo in various departments of colleges and universities, a trouble accompanied is that related operating personnel are confused about the information release and content openness. Firstly, they do not know what kind of information can be released by weibo, whether others' blog content can be transmitted, especially those of big men. If they can, exactly what kind of information can be transmitted. Secondly, there hasn't formed a unified regulation with regards related information release, especially when it comes to relevant information between different departments. Questions like 'whether can it be open?' 'To what degree can it be open?' are thorny problems.

\subsection{The lack of positive response from students and the social public}

In many cases, the current development of government affairs micro-blog in colleges and universities is only a single spark, and hasn't reach a point that can start a prairie fire. The main reason is the lack of active participation of all parties, such as college students, faculty members and the social public.This may be because of the fact that there is always no substantive content in university affairs weibo. It is just considered as a means used for school enlargement and the establishment of a good school image. On the other hand, this is because the propaganda and management of individual universities does not reach the designated position. Some departments and the leadership of government take into account of the possibility that government affairs micro-blog may expose some problems in the practical work of school, influence the school's reputation and image, and finally get the development of the universities endangered.

\subsection{No relevant settlement mechanism for weibo complaint}

One important reason for the fewer takers of university affairs weibo is probably that there's no settling mechanism of weibo complaint. This is a general problem facing weibo complaints. On the one hand, the content of the complaint is many and manifold. The result is that they can not be solved comprehensively in a short period of time, only limited to some major events that have a stronger response. The settlement of any tiny complaint, on the other hand, tends to get the involvement of the coordination of multiple teaching and managing departments. The cost of solving the problem is higher. 
3 THE BREAKTHROUGH OF THE DEVELOPMENTAL BOTTLENECK OF GOVERNMENT AFFAIRS MICRO-BLOG IN COLLEGES AND UNIVERSITIES

\subsection{Get it closely related with the actual work of colleges and universities}

To some extent, colleges and universities is a relatively independent community. In order to maintain the effective and orderly operation of the community, a lot of management and service work has to be done. Whether the work is accomplished efficaciously depends not only on the managers of the colleges and universities, but also on the attendees. Close communication between the two parties is very important; the government affairs micro-blog can meet this need. On the one hand, managers can give full play to weibo in passing related policy and information of the school quickly to the students and the relevant departments; in this way, college work can be done in a timely manner. On the other hand, some new problems that appear in the specific work can get feedback quickly through micro-blogging.

\subsection{Develop information release working mechanism}

The development of university administrative microblogging depends largely on the further improvement of information release mechanism. Then what should college leaders and relevant departments do? They should attach great importance to the advantages of government affairs micro-blog in colleges and universities, see the positive impact of weibo in the reform and development of colleges and universities, perfect the mechanism of the examination, approval, management and release of information, carry out the special operations personnel and competent leadership. By these means, the development of egovernment micro-blog can go on to a formalized and normalized orbit.

\subsection{Enhance the participation of students, teachers and the social public}

The positive role played by university affairs weibo is often dependent on the timely response from the students, teachers, and the social public, especially the fans' forwarding and comments. And to reach this point, active participation of students, teachers and the public are critically needed. First of all, we should start with changing the content of government affairs weibo, enhancing the transparency and effectiveness of government work in colleges and universities, making its content closely related with the life of the vast majority of students and teachers and even the development of the society. By this means, the government affairs micro-blog can intensify its attraction and arouse more attention for its future development. Second, the understanding of government affairs micro-blog among related university department leadership and staff should be transformed. E-government weibo should not be resisted because of the possible change to the ways of working and unnecessary trouble it brings.

\subsection{Implement the mechanism of weibo content settlement and management}

In order to solve the related problems involved during weibo interaction and to meet the need of respond to emergencies, colleges and universities should seriously study, establish, and improve the management and settlement of related problems. Once related problems appear, government affairs micro-blog can be used according to the preset mechanism of management and settlement to transmit the relevant content and problems directly to the specific disposal department and related personnel, asking specific disposal department and related personnel to solve the problems in time and make a positive response through government affairs micro-blog.

\subsection{Actively promote the leading cadre real-name weibo}

Universities should constantly encourage and actively support the leading cadre to open wei-bo under real name. They can either know the real life and state of thought of college students through browsing the content of weibo; they can, at the same time, guide the contemporary college students through the comments and remarks of public opinion because leaders have a great influence and popularity. This works especially when it comes to social hot and difficult issues. To give active response and to spread positive energy in the interaction of weibo will definitely contribute a lot to the cultivation of qualified successors for the modernization of socialism with Chinese characteristics.

\section{ACKNOWLEDGEMENTS}

This paper is a phase achievement of a humanistic and social science research project of the department of education in heilongjiang province in 2014, with the title being $O n$ the Dynamic Managing Mechanism of the Risk Prevention and Control of Integrity in Colleges and Universities (Item No. 12542284); It is also a phase achievement of preliminary provincial project of Mundanjiang Normal University, with the title being On Liu Shaoqi's Thought of Clean Government (Item No. sy201302). 


\section{REFERENCES}

[1] Shao, H. 2012. How much power does government affairs micro-blog in colleges and universities have? [EB/OL]. http://paper.dzwww.com/jjdb/data/20120305/html/4/conte nt_2.html.[2012-03-05].

[2] People's Daily online public opinion channel. Report on the development of weibo used by Chinese agencies and officials (3): seven tips to the weibo of government agencies and officials. [EB/OL]. http://www.people.com. $\mathrm{cn} / \mathrm{GB} / 209043 / 212786 / 14244765 . h t m l, 2011-03-26$.

\section{ABOUT THE AUTHOR}

Authors' brief introduction: Duan Manjiang (1979--), Male, Pucheng Shanxi China, master degree, lecturer in School of Marxim Mudanjiang Normal University; Research direction: Marxist ethics. Dong Yibing(1968--), Female, Mishan Heilongjiang China, doctoral degree, professor in School of Marxim Mudanjiang Normal University. Research direction: localization of Marxism in China. 